\title{
Bayesian Estimation of Shift Point in Poisson Model under Asymmetric Loss Functions
}

\author{
Uma Srivastava \\ Department of Mathematics and Statistics \\ DDU Gorakhpur University \\ Gorakhpur-273009,U.P.(INDIA) \\ uma_stat@yahoo.co.in
}

\begin{abstract}
The paper deals with estimating shift point which occurs in any sequence of independent observations $X_{1}, \ldots \ldots . X_{m}, X_{m+1}, \ldots . . X_{n}$ of Poisson model in statistical process control. This shift point occurs in the sequence when $X_{m}$ i.e. $\mathrm{m}$ life data are observed. The Bayes estimator on shift point ' $\mathrm{m}$ ' and before and after shift process means $\lambda_{1} \& \lambda_{2}$ are derived for symmetric and asymmetric loss functions under informative and non informative priors. The sensitivity analysis of Bayes estimators are carried out by simulation and numerical comparisons with R-programming. The results show the effectiveness of shift in sequence of Poisson distribution.
\end{abstract}

\section{Introduction}

In some real life applications, like physical systems manufacturing the items are often subject to abrupt shifts in the failure rate function, which are observed due to overhauls, major operations or specific maintenance activities, that is it may observed at some point of time instability in the sequence of life times. Such observed point is known as shift point. In such situations we are interest to detect the location where such a shift occurs and have estimate on the shift. In this paper we have considered the problem of estimating a single shift point in failure rate function when the observed variables are subject to random censoring. There are many studies on shift point problem in a sequence of random variables. Hinkley (1970) studied the shift point problem and considered a sequence of independent continuous random variables. In Hinkley's study, the maximum likelihood estimate was derived for three cases-when means of pre and post shift point are known but the shift point is unknown, when mean of pre shift point is known but the shift point and mean of post shift point are unknown and, when means of pre and post shift point and the shift point are unknown.

Most authors' investigations are based on the work of Hinkley (1970). For example, the shift point problem in a sequence of binomial variables is studied by Hinkley and Hinkley (1970); the shift point in a sequences of exponential and Poisson variables are investigated by Worsley (1986); Haccou, Meelis and Geer (1988); Estimation of shift points in a homogeneous Poisson process studied by Jandhyala and Fotopoulos (1999) and Boudjelaba, MacGibbon and Sawyer (2001); Fotopoulos and Jandhyala (2001). The study of homogeneous Poisson process and continuous time shift point problem in such Poisson process has been carried out by some authors. For example use of cumulating sum (CUSUM) control charts and exponentially weighted charts are studied by Montgomery (2001) and Wu et. al. (2004) to detect shift in target value in production process, 
when small shift $(<1.5 \sigma)$ occur.Lim et. al. (2002), Wu and Tiau (2005) and Zhang and Wu (2005) considered the applications of CUSUM control charts. Broemeling (1985) and Broemeling and Tsurumi (1987) provide a literature on structural shift which denotes a shift in one or more of the parameters in models from the Bayesian perspective. Its applications are very much useful in the models whose parameters cannot be clearly defined but in some way such models are involved with structural shift. Shift point study in Poisson process is very much useful in earthquake data.

The Bayesian inferential applications can play an important role in study of such problem of shift points. Many of statisticians like Chin and Broemeling (1980), Calabria and Pulcini (1994), Zacks (1983), Pandya and Jani (2006), Shah and Patel $(2007,2009)$, Chib (1998), Altissemo and Corradi (2003) and Fiteni (2004) studied the shift point Models in Bayesian framework.

In this paper the Bayes estimates of the mean parameters $\lambda_{1}$ and $\lambda_{2}$, for the sequences, before and after shift point ' $m$ ' of independent lifetimes from Poisson population and also Bayes estimate of shift point ' $m$ ', in the same sequence of independent lifetimes from Poisson population are derived for symmetric and asymmetric loss functions viz. squared error loss function, linex loss function, precautionary loss function and general entropy loss function under informative and non informative priors.A sensitivity analysis of these Bayes estimates has also been presented by simulation and numerical comparison study through $\mathrm{R}$ programming.

\section{Likelihood, Prior, Posterior and Marginal}

Let $x_{1}, x_{2}, \ldots, x_{n}(n \geq 3)$ be a sequence of observed discrete life times. First let observations $x_{1}, x_{2}, \ldots \ldots \ldots \ldots . . . ., x_{n}$ have come from Poisson distribution with probability mass function (pmf) as

$\mathrm{p}(\mathrm{x})=\frac{\mathrm{e}^{-\lambda} \lambda^{\mathrm{x}}}{\mathrm{x} !} \quad ; \mathrm{x}=0,1, \ldots, \lambda>0$

Poisson distribution occurs when there are events which do not occurs as outcomes of a definite number of trials of an experiment but which occur at random points of time and space wherein our interest lies only in the number of occurrences of the event, not in its non-occurrences.

Let ' $m$ ' is shift point in the observation which breaks the distribution in two sequences as $\left(x_{1}, x_{2}, \ldots, x_{m}\right) \&\left(x_{m+1}, \ldots, x_{n}\right)$.

The probability mass functions of the above sequences are

$\mathrm{p}_{1}(\mathrm{x})=\frac{\mathrm{e}^{-\lambda_{1} \lambda_{1}{ }^{\mathrm{x}}}}{\mathrm{x} !}$, wherex $=0,1, \ldots, \lambda_{1}>0$

$p_{2}(x)=\frac{e^{-\lambda_{2}} \lambda_{2}{ }^{x}}{x !}, \quad$ where $x=0,1, \ldots, \lambda_{2}>0$

The likelihood functions of p.m.f.'s of the sequences are 
$\mathrm{L}\left(\left(\lambda_{1} \mid \underline{\mathrm{x}}\right) \alpha \frac{\mathrm{e}^{-\mathrm{m} \lambda_{1}} \lambda_{1} \mathrm{~s}_{1 \mathrm{~m}}}{\mathrm{x}_{1} ! \ldots \ldots \mathrm{x}_{\mathrm{m}} !}\right.$

$\mathrm{L}\left(\left(\lambda_{2} \mid \underline{\mathrm{x}}\right) \alpha \frac{\mathrm{e}^{-(\mathrm{n}-\mathrm{m}) \lambda_{2} \lambda_{2}}\left(\mathrm{~S}_{1 \mathrm{n}}-\mathrm{S}_{1 \mathrm{~m})}\right.}{\mathrm{x}_{(\mathrm{m}+1)} ! \ldots . \mathrm{x}_{\mathrm{n}} !}\right.$

Where $S_{1 m}=\sum_{i=1}^{m} x_{i}$ and $S_{1 n}-S_{1 m}=\sum_{i=m+1}^{n} x_{i}$

and the joint Likelihood function is given by;

$L\left(\left(\lambda_{1} \lambda_{2} \mid \underline{x}\right) \quad \alpha \frac{e^{-m \lambda_{1}} \lambda_{1} S_{1 m}}{x_{1} ! \ldots . x_{m} !} \frac{e^{-(n-m) \lambda_{2}} \lambda_{2} S_{1 n}-S_{1 m}}{x_{m+1} ! \ldots . x_{n} !}\right.$

Suppose the marginal prior distributions of $\lambda_{1}, \lambda_{2}$ are natural conjugate prior

$\mathrm{g}_{1}\left(\lambda_{1}\right) \alpha \frac{\mathrm{b}_{1}^{\mathrm{a}_{1}}}{\Gamma \mathrm{a}_{1}} \lambda_{1}^{\mathrm{a}_{1}-1} \exp \left(-\mathrm{b}_{1} \lambda_{1}\right), \quad \mathrm{a}_{1}, \mathrm{~b}_{1}>0$

$\mathrm{g}_{2}\left(\lambda_{2}\right) \propto \frac{\mathrm{b}_{2}^{\mathrm{a}_{2}}}{\Gamma \mathrm{a}_{2}} \lambda_{2}^{\mathrm{a}_{2}-1} \exp \left(-\mathrm{b}_{2} \lambda_{2}\right), \quad \mathrm{a}_{2}, \mathrm{~b}_{2}>0$

We take the marginal prior distribution of shift point ' $m$ ' discrete uniform over the $\operatorname{set}\{1,2,3, \ldots \ldots(n-1)\}$,then

The joint prior distribution of $\lambda_{1}, \lambda_{2}$ and shift point ' $m$ ' is

$\mathrm{g}\left(\lambda_{1}, \lambda_{2}, \mathrm{~m}\right) \alpha \frac{\mathrm{b}_{1}^{\mathrm{a}_{1}} \mathrm{~b}_{2}^{\mathrm{a}_{2}}}{\Gamma \mathrm{a}_{1} \Gamma \mathrm{a}_{2}} \lambda_{1}^{\mathrm{a}_{1}-1} \lambda_{2}^{\mathrm{a}_{2}-1} \exp \left(-\mathrm{b}_{1} \lambda_{1}\right) \exp \left(-\mathrm{b}_{2} \lambda_{2}\right)$

Where $\lambda_{1}, \lambda_{2}>0 \& m=1, \ldots . .(n-1)$

The Joint posterior density of $\lambda_{1}, \lambda_{2}$ and $\mathrm{m}$ say $\pi\left(\lambda_{1}, \lambda_{2} ; \mathrm{m} \mid \underline{\mathrm{x}}\right)$ is obtained by using equations (6) and (9) as

$\Pi\left(\lambda_{1}, \lambda_{2} ; \mathrm{m} \mid \underline{\mathrm{x}}\right)=\frac{\mathrm{e}^{-\left(\mathrm{b}_{1}+\mathrm{m}\right) \lambda_{1} \lambda_{1}^{\left(\mathrm{a}_{1}+\mathrm{S}_{1 \mathrm{~m}}-1\right)} \mathrm{e}^{-\left(\mathrm{b}_{2}+\mathrm{n}-\mathrm{m}\right) \lambda_{2}} \lambda_{2}^{\left(\mathrm{a}_{2}+\mathrm{S}_{1 \mathrm{n}}-\mathrm{S}_{1 \mathrm{~m}}-1\right)}}}{\Psi\left(\mathrm{a}_{1}, \mathrm{a}_{2}, \mathrm{~b}_{1}, \mathrm{~b}_{2}, \mathrm{~m}, \mathrm{n}\right)}$

Where,

$\psi\left(\mathrm{a}_{1}, \mathrm{a}_{2}, \mathrm{~b}_{1}, \mathrm{~b}_{2}, \mathrm{~m}, \mathrm{n}\right)=\sum_{\mathrm{m}=1}^{(\mathrm{n}-1)}\left[\frac{\Gamma\left(\mathrm{a}_{1}+\mathrm{s}_{1 \mathrm{~m})}\right.}{\left(\mathrm{b}_{1}+\mathrm{m}\right)^{\left(\mathrm{a}_{1}+\mathrm{s}_{1 \mathrm{~m})}\right.}} \frac{\Gamma\left(\mathrm{a}_{2}+\mathrm{s}_{1 \mathrm{n}}-\mathrm{s}_{1 \mathrm{~m}}\right)}{\left(\mathrm{b}_{2}+\mathrm{n}-\mathrm{m}\right)^{\left(\mathrm{a}_{2}+\mathrm{s}_{1 \mathrm{n}}-\mathrm{S}_{1 \mathrm{~m}}\right)}} \mid\right.$

The marginal posterior distribution of shift point ' $m$ ' using the eqns. (6), (7) and $(8)$ is

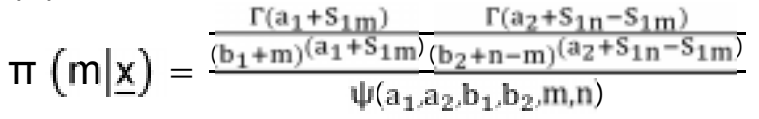

The marginal posterior distribution of $\lambda_{1}$, using the eqns (6)and (7) is

$\pi\left(\lambda_{1} \mid \underline{x}\right)=\frac{\sum_{m} \mathrm{e}^{-\left(b_{1}+m\right) \lambda_{1}} \lambda_{1}^{\left(a_{1}+s_{1 m}-1\right)}-\frac{\Gamma\left(a_{2}+s_{1 n}-S_{1 m}\right)}{\left(b_{2}+n-m\right)^{\left(a_{2}+S_{1 n}-s_{1 m}\right)}}}{\psi\left(a_{1}, a_{2}, b_{1}, b_{2}, m, n\right)}$

The marginal posterior distribution of $\lambda_{2}$, using the eqns (6) and (8) is

$\Pi\left(\lambda_{2} \mid \underline{x}\right)=\frac{\sum_{m}\left[\frac{\Gamma\left(a_{1}+S_{1 m}\right)}{\left(b_{1}+m\right)^{\left(a_{1}+S_{1 m}\right)}} \mid e^{-\left(b_{2}+(n-m) \lambda_{2}\right)} \lambda_{2}^{\left(a_{2}+S_{1 n}-s_{1 m}-1\right)}\right.}{\psi\left(a_{1}, a_{2}, b_{1}, b_{2}, m, n\right)}$

\section{Bayes Estimators under Asymmetric Loss Functions}

In decision theory the loss criterion is specified in order to obtain best estimator. The simplest form of loss function is squared error loss function (SELF) which assigns equal magnitudes to both positive and negative errors. However this assumption may be inappropriate in most of the estimation problems. Some time overestimation leads to many serious consequences. In such situation many authors found the asymmetric loss functions, more appropriate. In this paper we have considered some of the asymmetric loss functions vizlinexloss function (LLF) suggested and studied by Varian (1975), Zellner (1986), Basu and 
Ebrahimi (1991), general entropy loss functions (GELF) by Calabria and Pulcini (1996) and precautionary loss function (PLE) studied by Norstrom(1996). Such asymmetric loss functions are also studied by Ohtani (1995), Parsian and Kirmani (2002), Braess and Dette (2004) and Pandyaet. al. (2004).Aitchison and Dunsmore(1975) and Berger(1985) are the important references of such type of Bayesian inferential problems.

\subsection{Bayes Estimators under Squared Error Loss Functions (SELF)}

From a decision - theoretical view point, in order to select value as representing on 'best' estimator, a loss function must be specified. In this section we consider SELF.

The Bayes estimate of a generic parameter (or function thereof) $\lambda$ based on a SELF is given by

$$
L_{1}(\lambda, d)=(\lambda-d)^{2} \text {, Where ' } d \text { ' is a decision rule to estimate } \lambda \text {, is posterior }
$$
mean. For the shift point ' $m$ ', which is a non negative integer quantity $m=1,2, \ldots .,(n-1)$, the loss function is defined as

$\mathbf{L}_{1}\left(\mathrm{~m}, \widehat{\mathrm{m}}_{\mathrm{s}}\right)=\left(\mathrm{m}-\widehat{\mathrm{m}}_{\mathrm{s}}\right)^{2}$

where, $\widehat{\mathrm{m}}_{\mathrm{s}}=1, \ldots,(\mathrm{n}-1)$ is the smallest integer greater than analytical solution.

The Bayes estimate $\widehat{\mathrm{m}}_{\mathrm{BS}}$ of ' $\mathrm{m}$ ' under SELF using marginal posterior density equation (12) is given as

$\widehat{\mathrm{m}}_{\mathrm{BS}}=\sum_{\mathrm{m}} \mathrm{m} \pi(\mathrm{m} \mid \underline{\mathrm{x}})$

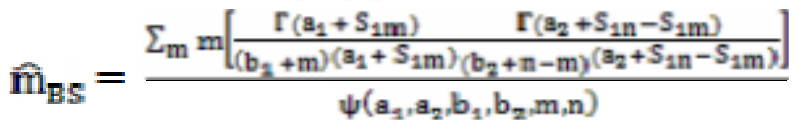

The Bayes estimate $\hat{\lambda}_{1 \mathrm{BS}}$ of $\lambda_{1}$ under SELF using marginal posterior density equation (13) is given by

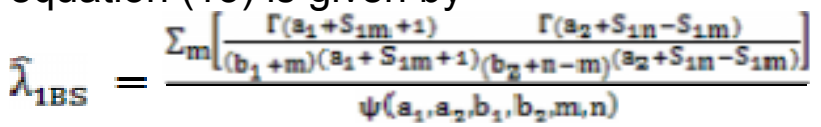

$\widehat{\lambda}_{1 \mathrm{BS}}=\frac{\psi\left[\left(\mathrm{a}_{1}+1\right), \mathrm{a}_{2}, \mathrm{~b}_{1}, \mathrm{~b}_{2}, \mathrm{~m}, \mathrm{n}\right]}{\psi\left(\mathrm{a}_{1}, \mathrm{a}_{2}, \mathrm{~b}_{2}, \mathrm{~b}_{2}, \mathrm{~m}, \mathrm{n}\right)}$

The Bayes estimate $\hat{\lambda}_{2 \mathrm{BS}}$ of $\lambda_{2}$ under SELF using marginal posterior density equation (14) is given by

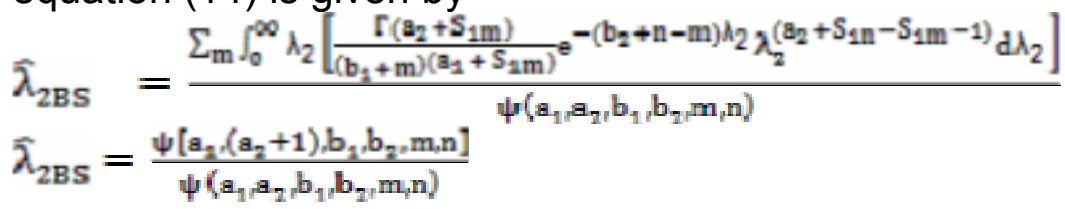

\subsection{Bayes Estimators under Linex Loss function (LLF)}

The asymmetric loss function given by Varian(1975), known as linex loss function(LLF), is defined as

$L_{2}(\lambda, d)=\exp \left[\alpha_{1}(d-\lambda)\right]-\alpha_{1}(d-\lambda)-1 ; \alpha_{1} \neq 0$

Where $d$ is the decision rule to estimate unknown parameter $\lambda$. 
For shift point $m$, the loss function is defined as

$$
L_{2}\left(m, \widehat{m}_{B L}\right)=\exp \left[\alpha_{1}\left(\widehat{m}_{B L}-m\right)\right]-\alpha_{1}\left(\widehat{m}_{B L}-m\right)-1 ; \alpha_{1} \neq 0
$$

The Bayes estimate $\widehat{m}_{B L}$ of $\mathrm{m}$ under LLF eqn.(21) using marginal posterior of eqn. (12), is given by

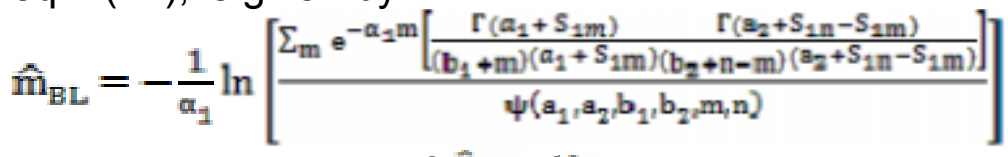

The Bayes estimate of $\hat{\lambda}_{1 B L}$ of $\lambda_{1}$ using marginal posterior of eqn. (13) under LLF eqn.(20) is given by

$$
\begin{aligned}
& \hat{\lambda}_{1 B L}=-\frac{1}{\alpha_{1}} \ln \left[\frac{\sum_{m} \frac{\Gamma\left(a_{1}+s_{1 m}\right)}{\left(b_{1}+m+\alpha_{1}\right)^{\left(a_{1}+s_{1 m}\right)}} \frac{\Gamma\left(a_{2}+s_{1 n}-s_{1 m}\right)}{\left(b_{2}+n-m\right)^{\left(a_{2}+s_{1 n}-s_{1 m}\right)}}}{\psi\left(a_{1}, a_{2}, b_{1}, b_{2}, m, n\right)}\right] \\
& \hat{\lambda}_{1 B L}=-\frac{1}{\alpha_{1}} \ln \left[\frac{\psi\left[a_{1},\left(b_{1}+\alpha_{1}\right), a_{2}, b_{2}, m, n\right]}{\psi\left(a_{1}, a_{2}, b_{1}, b_{2}, m_{1}, n\right)}\right]
\end{aligned}
$$

The Bayes estimate of $\hat{\lambda}_{2 B L}$ of $\lambda_{2}$ using marginal posterior of eqn. (14) under LLF eqn.(20) is given by

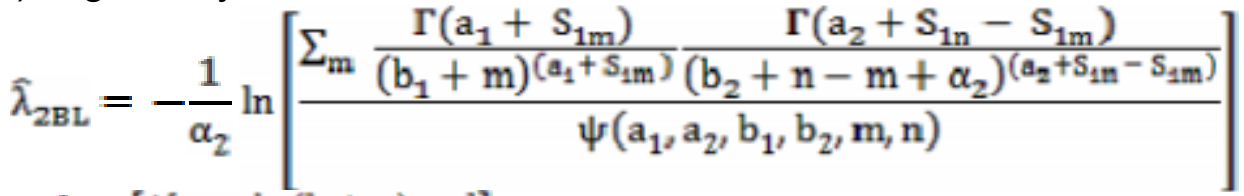

$$
\begin{aligned}
& \widehat{\lambda}_{2 \mathrm{BL}}=-\frac{1}{\alpha_{2}} \ln \left[\frac{\psi\left[\mathrm{a}_{1}, \mathrm{a}_{2}, \mathrm{~b}_{1},\left(\mathrm{~b}_{2}+\alpha_{2}\right), \mathrm{m}, \mathrm{n}\right]}{\psi\left(\mathrm{a}_{2}, \mathrm{a}_{2}, \mathrm{~b}_{1}, \mathrm{~b}_{2}, \mathrm{~m}, \mathrm{n}\right)}\right]
\end{aligned}
$$

\subsection{Bayes Estimators under Precautionary Loss Function (PLF)}

Norstrom(1996) introduced an alternative asymmetric loss function and also presented a general class of precautionary loss function with quadratic loss function as a special case. These loss functions approach infinitely near the origin to prevent the overestimation and thus giving conservative estimators, especially when low failure rates are being estimated which may lead to serious consequences.

A very useful and simple asymmetric precautionary loss function is given by

$$
L_{3}(\lambda, \hat{\lambda})=\frac{(\lambda, \hat{\lambda})^{2}}{\bar{\lambda}}
$$

The posterior expectation is given by

$$
E_{\rho}=\left[L_{3}(\lambda-\hat{\lambda})\right]=E_{\rho}\left(\frac{\lambda^{2}}{\hat{\lambda}}\right)+E_{\rho}(\hat{\lambda})-2 E_{\rho}(\lambda)
$$

The value of $\hat{\lambda}$ that minimizes (26) is given by $\hat{\lambda}_{B P}$, the Bayes estimator of $\lambda$ under precautionary loss function is obtain by solving the equation;

$$
\begin{aligned}
& \frac{\partial}{\partial \widehat{\theta}} E_{\rho} L(\lambda, \hat{\lambda})=0 \\
\Rightarrow & \widehat{\theta}_{B P}=E_{\rho}\left(\lambda^{2}\right)^{\frac{3}{2}}
\end{aligned}
$$

For shift point $\mathrm{m}$, the loss function defined as

$$
L_{3}\left(m, \widehat{m}_{B P}\right)=\frac{\left(m-\widehat{m}_{B P}\right)^{2}}{\widehat{m}_{B P}}
$$


The Bayes estimate $\widehat{\mathrm{m}}_{\mathbb{B P}}$ of $\mathrm{m}$ using the marginal posterior distribution equation $(12)$ is

$$
\widehat{m}_{B P}=\left[\frac{\Sigma_{m} m^{2} \frac{\Gamma\left(a_{1}+S_{2 m}\right)}{\left.\left(b_{1}+m\right)\left(a_{1}+S_{1 m}\right)\left(b_{2}+n-m\right)^{\left(a_{2}+S_{1 n}-S_{1 m}\right.}\right)}}{\psi\left(a_{1}, a_{2}, b_{1}, b_{2}, m, n\right)}\right]^{1 / 2}
$$

The Bayes estimator ${\tilde{\lambda_{1 R D}}}_{\text {R }}$ of $\lambda_{\mathbf{1}}$ under PLF using the marginal posterior distribution equation (13) is

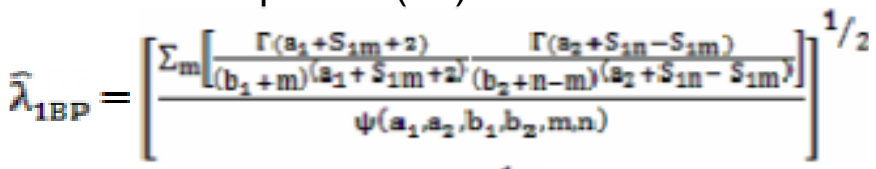

$$
\begin{aligned}
& \widehat{\lambda}_{1 \mathrm{BP}}=\left[\frac{\psi\left[\left(\mathrm{a}_{1}+2\right), \mathrm{a}_{2}, \mathrm{~b}_{1}, \mathrm{~b}_{2}, \mathrm{~m}, \mathrm{n}\right]}{\psi\left(\mathrm{a}_{1}, \mathrm{a}_{2}, \mathrm{~b}_{1}, \mathrm{~b}_{2}, \mathrm{~m}, \mathrm{n}\right)}\right]^{1 / 2}
\end{aligned}
$$

The Bayes estimate ${\widehat{\lambda_{2 D D}}}_{\text {of }} \lambda_{2}$ under PLF using the marginal posterior distribution equation (14) is

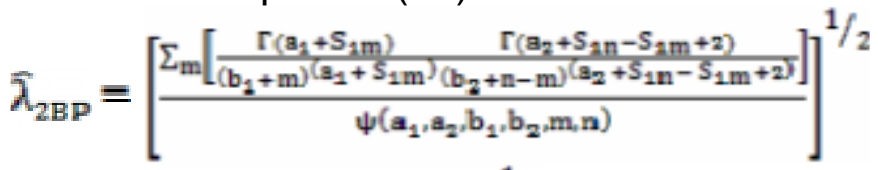

$$
\begin{aligned}
& \hat{\lambda}_{2 \mathrm{BP}}=\left[\frac{\psi\left[\mathrm{a}_{1},\left(\mathrm{a}_{2}+2\right), \mathrm{b}_{1}, \mathrm{~b}_{2}, \mathrm{~m}, \mathrm{n}\right]}{\psi\left(\mathrm{a}_{1}, \mathrm{a}_{2}, \mathrm{~b}_{1}, \mathrm{~b}_{2}, \mathrm{~m}, \mathrm{n}\right)}\right]^{1 / 2}
\end{aligned}
$$

\subsection{Bayes estimators under General Entropy Loss Function (GELF)}

Occasionally, the use of symmetric loss function, namely SELF, was found inappropriate, since for example, an overestimation of the reliability function usually much more serious than an underestimation. Here was considered asymmetric loss function namely general entropy loss function (GELF) proposed by Calabria and Pulcini (1994), is given by

$$
L_{4}(\lambda, d)=\left(\frac{d}{\lambda}\right)^{\alpha_{2}}-\alpha_{2} \ln \left(\frac{d}{\lambda}\right)-1 ;\left(\alpha_{2} \neq 0\right)
$$

whereas for the shift point $m$, the loss function is defined as

$$
L_{4}\left(m, \widehat{m}_{B E}\right)=\left(\frac{\vec{m}_{B E}}{m}\right)^{\alpha_{2}}-\alpha_{2} \ln \left(\frac{\widehat{m}_{B E}}{m}\right)-1 ;\left(\alpha_{2} \neq 0\right)
$$

where $\alpha_{2} \neq 0, m=1,2, \ldots,(n-1)$ and $\widehat{m}_{B E}=1,2, \ldots,(n-1)$. Here $\widehat{m}_{B E}$ is the smalllest integer greater than the analytical solution. In GELF sign and magnitude of $\alpha_{2}$ reflects the degree of asymmetry.

The Bayes estimate $\widehat{\mathrm{m}}_{\mathrm{BE}}$ of $\mathrm{m}$ under GELF using marginal posterior distribution eqn.(12) is

$\widehat{\mathrm{m}}_{\mathrm{BE}}=\left[\frac{\sum_{\mathrm{m}} \mathrm{m}^{-\alpha_{2}} \frac{\mathrm{r}\left(\mathrm{a}_{1}+S_{1 \mathrm{~m}}\right)}{\left(\mathrm{b}_{2}+\mathrm{m}\right)\left(\mathrm{a}_{1}+S_{1 m}\right)\left(\mathrm{b}_{2}+\mathrm{n}-\mathrm{m}\right)\left(\mathrm{s}_{2}+\mathrm{s}_{1 \mathrm{n}}-S_{1 \mathrm{~m}}\right)}}{\psi\left(\mathrm{a}_{1}, \mathrm{~s}_{2}, \mathrm{~b}_{1}, \mathrm{~b}_{2}, \mathrm{~m}, \mathrm{n}\right)}\right]^{-1 / \alpha_{2}}$

The Bayes Estimate $\hat{\lambda}_{1 B E}$ of $\lambda_{1}$ under GELF using marginal posterior distribution eqn.(13), we get

$$
\left.\hat{\lambda}_{1 \mathrm{BE}}=\left[\frac{\Sigma_{m}\left[\frac{\Gamma\left(a_{1}+S_{2 m}-\alpha_{2}\right)}{\left(\mathbf{b}_{1}+m\right)\left(a_{1}+S_{1 m}-\alpha_{2}\right)\left(b_{2}+n-m\right)\left(a_{2}+S_{1 n}-S_{1 m}\right)}\right]}{\Psi\left(a_{1}, a_{2}, b_{1}, b_{2}, m, n\right)}\right]\right]^{-1 / \alpha_{2}}
$$




$$
\hat{\lambda}_{1 \mathrm{BE}}=\left[\frac{\left.\psi\left[\left(a_{1}-a_{2}\right), a_{2}, b_{1}, b_{2}, m, n\right)\right]}{\psi\left(a_{1}, a_{2}, b_{1}, b_{2}, m, n\right)}\right]^{-1 / \alpha_{2}}
$$

The Bayes estimate $\hat{\lambda}_{2 \mathrm{BE}}$ of $\lambda_{2}$ under GELF using marginal posterior distribution eqn.(14) is

$$
\begin{gathered}
\bar{\lambda}_{2 B E}=\left[\frac{\Sigma_{m}\left[\frac{\Gamma\left(a_{1}+S_{2 m}\right)}{\left(b_{1}+m\right)\left(a_{1}+S_{1 m}\right)\left(b_{2}+n-m\right)\left(a_{2}+S_{1 n}-S_{1 m}-a_{2}\right)}\right]}{\psi\left(a_{1}, a_{2}, b_{1}, b_{2}, m, n\right)}\right]^{-1 / a_{2}} \\
\hat{\lambda}_{2 B B}=\left[\frac{\psi\left[a_{1},\left(a_{2}-a_{2}\right), b_{2}, b_{2}, m, n\right]}{\psi\left(a_{1}, a_{2}, b_{1}, b_{2}, m, n\right)}\right]^{-1 / \alpha_{2}}
\end{gathered}
$$

\section{Numerical Comparison}

We have generated 20 random observations from poisson distribution with mean $\lambda=2$. The observed data mean is $\lambda=2.45$ and variance is 2.47 . Let the shift in sequence is at $12^{\text {th }}$ observation, so the means of both sequences $\left(x_{1}, x_{2}, \ldots, x_{m}\right)$ and $\left(x_{(m+1)}, x_{(m+2)}, \ldots, x_{n}\right)$ are $\lambda_{1}=2.33, \lambda_{2}=2.63$. If the target value of $\lambda_{1}$ is unknown, its estimating $\left(\hat{\lambda}_{1}\right)$ is given by the mean of first $m$ sample observation given $\mathrm{m}=12, \lambda=2.3$.

Table 1

\begin{tabular}{|c|c|c|c|c|c|c|c|c|c|}
\hline 1 & 2 & 3 & 4 & 5 & 6 & 7 & 8 & 9 & 10 \\
\hline 4 & 3 & 3 & 2 & 2 & 2 & 2 & 0 & 3 & 0 \\
\hline 11 & 12 & 13 & 14 & 15 & 16 & 17 & 18 & 19 & 20 \\
\hline 2 & 5 & 3 & 0 & 4 & 6 & 2 & 3 & 1 & 2 \\
\hline
\end{tabular}

We have again generated the random samples of different sizes $15,20,25$. The Shift point would lie between 1 to 20 and let the shift point is 12 . The Bayes estimators of $\lambda_{1}, \lambda_{2}$ and shift point 'm' are calculated under Squared error loss function, Linex loss function, Precautionary loss function and General entropy loss function by making programs in R-2.11.1 statistical software. We have repeated these steps for 500 times to calculate the respective M.S.E.'s of various Bayes estimators by making program in R-2.11.1 and analyzed the data for comparisons and conclusions.

\section{Sensitivity Analysis of Bayes Estimates}

In this section we have studied the sensitivity of the Bayes estimators of $\lambda_{1}, \lambda_{2}$ and shift point ' $m$ ' with respect to the parameters of prior distribution $a_{1}, b_{1}, a_{2}$ and $b_{2}$. We have computed the Bayes estimators of $\mathrm{m}, \lambda_{1}$ and $\lambda_{2}$ under SELF, LLF, PLF and GELF considering different set of values of prior parameters $a_{1}=1.50(0.25) 2.25, b_{1}=1.75(0.25) 2.50$ and $a_{2}=1.8(0.20) 2.40$, and $b_{2}=2.0(0.25) 2.75$.We have also considered different sample sizes $n=15(05) 25$. 
Table 2: Bayes Estimates of $m, \lambda_{1} \& \lambda_{2}$ and their respective M.S.E.'s under SELF and LLF

\begin{tabular}{|c|c|c|c|c|c|c|c|c|}
\hline$\left(a_{1}, b_{1}\right)$ & $\left(a_{2}, b_{2}\right)$ & $\mathbf{n}$ & $\widehat{m}_{B S}$ & $\hat{\lambda}_{1 B S}$ & $\hat{\lambda}_{2 B S}$ & $\widehat{m}_{B L}$ & $\hat{\lambda}_{1 B L}$ & $\hat{\lambda}_{2 B L}$ \\
\hline \multirow[t]{3}{*}{$(1.5,1.75)$} & $(1.8,2.0)$ & 15 & $\begin{array}{c}10 \\
(25.283)\end{array}$ & $\begin{array}{c}1.041 \\
(0.501)\end{array}$ & $\begin{array}{c}0.656 \\
(1.001)\end{array}$ & $\begin{array}{c}13 \\
(0.195)\end{array}$ & $\begin{array}{c}1.964 \\
(1.412)\end{array}$ & $\begin{array}{c}1.281 \\
(0.963)\end{array}$ \\
\hline & & 20 & $\begin{array}{c}6 \\
(32.697)\end{array}$ & $\begin{array}{c}0.684 \\
(1.408)\end{array}$ & $\begin{array}{c}1.262 \\
(0.037)\end{array}$ & $\begin{array}{c}17 \\
(9.087)\end{array}$ & $\begin{array}{c}1.409 \\
(1.263)\end{array}$ & $\begin{array}{c}2.364 \\
(0.026)\end{array}$ \\
\hline & & 25 & $\begin{array}{c}10 \\
(26.920)\end{array}$ & $\begin{array}{c}0.978 \\
(0.024)\end{array}$ & $\begin{array}{c}0.979 \\
(2.431)\end{array}$ & $\begin{array}{c}22 \\
(63.514)\end{array}$ & $\begin{array}{c}2.039 \\
(0.014)\end{array}$ & $\begin{array}{c}1.795 \\
(2.506)\end{array}$ \\
\hline \multirow[t]{3}{*}{$(1.75,2.0)$} & $(2.0,2.25)$ & 15 & $\begin{array}{c}9 \\
(3.117)\end{array}$ & $\begin{array}{c}1.054 \\
(0.019)\end{array}$ & $\begin{array}{c}0.924 \\
(1.095)\end{array}$ & $\begin{array}{c}13 \\
(0.741)\end{array}$ & $\begin{array}{c}2.019 \\
(0.005)\end{array}$ & $\begin{array}{c}2.021 \\
(0.776)\end{array}$ \\
\hline & & 20 & $\begin{array}{c}12 \\
(0.007)\end{array}$ & $\begin{array}{c}0.933 \\
(0.169)\end{array}$ & $\begin{array}{c}0.849 \\
(1.383)\end{array}$ & $\begin{array}{c}18 \\
(18.823)\end{array}$ & $\begin{array}{c}1.668 \\
(0.140)\end{array}$ & $\begin{array}{c}1.691 \\
(1.175)\end{array}$ \\
\hline & & 25 & $\begin{array}{c}17 \\
(4.920)\end{array}$ & $\begin{array}{c}0.775 \\
(0.204)\end{array}$ & $\begin{array}{c}0.734 \\
(0.079)\end{array}$ & $\begin{array}{c}23 \\
(100.676)\end{array}$ & $\begin{array}{c}1.293 \\
(0.170)\end{array}$ & $\begin{array}{c}1.480 \\
(0.021)\end{array}$ \\
\hline \multirow[t]{3}{*}{$(2.0,2.25)$} & $(2.20,2.5)$ & 15 & $\begin{array}{c}10 \\
(22.526)\end{array}$ & $\begin{array}{c}0.975 \\
(0.594)\end{array}$ & $\begin{array}{c}0.416 \\
(0.304)\end{array}$ & $\begin{array}{c}12 \\
(0.641)\end{array}$ & $\begin{array}{c}1.851 \\
(0.339)\end{array}$ & $\begin{array}{c}0.722 \\
(0.191)\end{array}$ \\
\hline & & 20 & $\begin{array}{c}8 \\
(21.463)\end{array}$ & $\begin{array}{c}1.152 \\
(1.306)\end{array}$ & $\begin{array}{c}0.791 \\
(0.057)\end{array}$ & $\begin{array}{c}19 \\
(40.432)\end{array}$ & $\begin{array}{c}1.538 \\
(0.001)\end{array}$ & $\begin{array}{c}1.229 \\
(0.494)\end{array}$ \\
\hline & & 25 & $\begin{array}{c}12 \\
(27.310)\end{array}$ & $\begin{array}{c}1.141 \\
(1.420)\end{array}$ & $\begin{array}{c}0.830 \\
(0.225)\end{array}$ & $\begin{array}{c}21 \\
(71.862)\end{array}$ & $\begin{array}{c}1.584 \\
(0.009)\end{array}$ & $\begin{array}{c}1.155 \\
(0.617)\end{array}$ \\
\hline \multirow[t]{3}{*}{$(2.25,2.50)$} & $(2.40,2.75)$ & 15 & $\begin{array}{c}8 \\
(15.672)\end{array}$ & $\begin{array}{c}1.132 \\
(0.513)\end{array}$ & $\begin{array}{c}0.733 \\
(0.431)\end{array}$ & $\begin{array}{c}17 \\
(18.368)\end{array}$ & $\begin{array}{c}1.366 \\
(0.094)\end{array}$ & $\begin{array}{c}1.101 \\
(0.552)\end{array}$ \\
\hline & & 20 & $\begin{array}{c}10 \\
(6.542) \\
\end{array}$ & $\begin{array}{c}0.765 \\
(0.846)\end{array}$ & $\begin{array}{c}0.655 \\
(1.125) \\
\end{array}$ & $\begin{array}{c}19 \\
(39.143)\end{array}$ & $\begin{array}{c}1.525 \\
(0.055)\end{array}$ & $\begin{array}{c}1.176 \\
(0.553) \\
\end{array}$ \\
\hline & & 22 & $\begin{array}{c}19 \\
(54.225)\end{array}$ & $\begin{array}{c}1.507 \\
(0.007)\end{array}$ & $\begin{array}{c}0.948 \\
(0.556)\end{array}$ & $\begin{array}{c}21 \\
(70.215)\end{array}$ & $\begin{array}{c}1.618 \\
(0.001)\end{array}$ & $\begin{array}{c}1.164 \\
(0.550)\end{array}$ \\
\hline
\end{tabular}

The Bayes estimates of the shift point ' $\mathrm{m}$ ' and the parameters $\lambda_{1}$ and $\lambda_{2}$ are given in table-2 under SELF and LLF and the Bayes estimates of the shift point ' $\mathrm{m}$ ' and the parameters $\lambda_{1}$ and $\lambda_{2}$ are given in table-3 under PLF and GELF. Their respective mean squared errors (M.S.E's) are calculated by repeating this process 500 times and presented in same table in small parenthesis under the estimated values of parameters. 
Bayesian Estimation of Shift Point in Poisson Model under Asymmetric Loss Functions

Table 3: Bayes Estimates of $m, \lambda_{1} \& \lambda_{2}$ and their respective M.S.E.'s under PLF and GELF

\begin{tabular}{|c|c|c|c|c|c|c|c|c|}
\hline$\left(a_{1}, b_{1}\right)$ & $\left(a_{2}, b_{2}\right)$ & $\mathbf{n}$ & $\widehat{m}_{B P}$ & $\hat{\lambda}_{1 B P}$ & $\hat{\lambda}_{2 B P}$ & $\widehat{\boldsymbol{m}}_{B E}$ & $\bar{\lambda}_{1 B E}$ & $\hat{\lambda}_{2 B E}$ \\
\hline \multirow[t]{3}{*}{$(1.8,2.3)$} & $(1.3,1.55)$ & 18 & $\begin{array}{c}16 \\
(14.956)\end{array}$ & $\begin{array}{c}1.294 \\
(0.012)\end{array}$ & $\begin{array}{c}1.027 \\
(0.305)\end{array}$ & $\begin{array}{c}14 \\
(11.453)\end{array}$ & $\begin{array}{c}1.141 \\
(0.152)\end{array}$ & $\begin{array}{c}1.029 \\
(.0 .495)\end{array}$ \\
\hline & & 20 & $\begin{array}{c}18 \\
(34.352)\end{array}$ & $\begin{array}{c}1.558 \\
(0.025)\end{array}$ & $\begin{array}{c}0.995 \\
(0.356)\end{array}$ & $\begin{array}{c}17 \\
(31.143)\end{array}$ & $\begin{array}{c}1.399 \\
(0.567)\end{array}$ & $\begin{array}{c}1.049 \\
(0.136)\end{array}$ \\
\hline & & 22 & $\begin{array}{c}20 \\
(62.358) \\
\end{array}$ & $\begin{array}{c}1.750 \\
(0.006) \\
\end{array}$ & $\begin{array}{c}1.135 \\
(0.357) \\
\end{array}$ & $\begin{array}{c}20 \\
(58.017) \\
\end{array}$ & $\begin{array}{c}1.591 \\
(0.366) \\
\end{array}$ & $\begin{array}{c}1.238 \\
(0.075) \\
\end{array}$ \\
\hline \multirow[t]{3}{*}{$(1.9,2.4)$} & $(1.4,1.65)$ & 18 & $\begin{array}{c}16 \\
(15.464)\end{array}$ & $\begin{array}{c}1.724 \\
(0.349)\end{array}$ & $\begin{array}{c}1.039 \\
(0.321)\end{array}$ & $\begin{array}{c}15 \\
(12.964)\end{array}$ & $\begin{array}{c}1.530 \\
(0.479)\end{array}$ & $\begin{array}{c}1.044 \\
(0.171)\end{array}$ \\
\hline & & 20 & $\begin{array}{c}18 \\
(31.803)\end{array}$ & $\begin{array}{c}1.555 \\
(0.003)\end{array}$ & $\begin{array}{c}1.146 \\
(0.376)\end{array}$ & $\begin{array}{c}17 \\
(27.638)\end{array}$ & $\begin{array}{c}1.396 \\
(0.276)\end{array}$ & $\begin{array}{c}1.199 \\
(0.208)\end{array}$ \\
\hline & & 22 & $\begin{array}{c}19 \\
(56.149)\end{array}$ & $\begin{array}{c}1.434 \\
(0.363)\end{array}$ & $\begin{array}{c}1.156 \\
(0.218)\end{array}$ & $\begin{array}{c}21 \\
(71.552)\end{array}$ & $\begin{array}{c}1.597 \\
(0.001)\end{array}$ & $\begin{array}{c}1.457 \\
(0.422)\end{array}$ \\
\hline \multirow[t]{3}{*}{$(2.0,2.5)$} & $(1.5,1.75)$ & 18 & $\begin{array}{c}16 \\
(15.739)\end{array}$ & $\begin{array}{c}1.559 \\
(0.012)\end{array}$ & $\begin{array}{c}1.008 \\
(0.483)\end{array}$ & $\begin{array}{c}14 \\
(12.964)\end{array}$ & $\begin{array}{c}1.379 \\
(0.479)\end{array}$ & $\begin{array}{c}1.009 \\
(0.171)\end{array}$ \\
\hline & & 20 & $\begin{array}{c}17 \\
(28.788)\end{array}$ & $\begin{array}{c}1.455 \\
(0.003)\end{array}$ & $\begin{array}{c}1.053 \\
(0.381)\end{array}$ & $\begin{array}{c}16 \\
(20.505)\end{array}$ & $\begin{array}{c}1.303 \\
(2.045)\end{array}$ & $\begin{array}{c}0.877 \\
(0.321)\end{array}$ \\
\hline & & 22 & $\begin{array}{c}20 \\
(60.529)\end{array}$ & $\begin{array}{c}1.506 \\
(0.002)\end{array}$ & $\begin{array}{c}1.042 \\
(0.467)\end{array}$ & $\begin{array}{c}19 \\
(54.989)\end{array}$ & $\begin{array}{c}1.365 \\
(2.012)\end{array}$ & $\begin{array}{c}0.954 \\
(0.352)\end{array}$ \\
\hline \multirow[t]{3}{*}{$(2.1,2.6)$} & $(1.6,1.85)$ & 18 & $\begin{array}{c}16 \\
(10.199) \\
\end{array}$ & $\begin{array}{c}1.304 \\
(0.107) \\
\end{array}$ & $\begin{array}{c}1.054 \\
(0.396) \\
\end{array}$ & $\begin{array}{c}13 \\
(3.816) \\
\end{array}$ & $\begin{array}{c}1.140 \\
(2.161) \\
\end{array}$ & $\begin{array}{c}0.999 \\
(0.407) \\
\end{array}$ \\
\hline & & 20 & $\begin{array}{c}18 \\
(25.497)\end{array}$ & $\begin{array}{c}1.453 \\
(0.067)\end{array}$ & $\begin{array}{c}1.093 \\
(0.399)\end{array}$ & $\begin{array}{c}16 \\
(16.350)\end{array}$ & $\begin{array}{c}1.300 \\
(2.147)\end{array}$ & $\begin{array}{c}1.051 \\
(0.397)\end{array}$ \\
\hline & & 22 & $\begin{array}{c}19 \\
(55.891)\end{array}$ & $\begin{array}{c}1.542 \\
(0.002)\end{array}$ & $\begin{array}{c}1.071 \\
(0.387)\end{array}$ & $\begin{array}{c}19 \\
(48.764)\end{array}$ & $\begin{array}{c}1.398 \\
(2.027)\end{array}$ & $\begin{array}{c}0.093 \\
(0.387)\end{array}$ \\
\hline
\end{tabular}

From the above tables we conclude that -

The Bayes estimates of $\hat{\boldsymbol{\lambda}}_{1}$ under PLF and SELF are seem to be efficient as the numerical values of their mse's are smaller for $\hat{\lambda}_{1 B S}$ and $\hat{\lambda}_{1 B P}$ in comparison with other estimates of the parameters under different loss functions. The Bayes estimates of both parameters are robust with accurate choice of prior parameters and sample size. The robustness of the Bayes estimates of shift point ' $m$ ' are shown by calculating its expected values and mse's under all considered loss functions. The Bayes estimates of shift point ' $m$ ' under SELF are much effective and nearer to the considered value of shift point ' $m$ ' for smaller values of the prior parameters and also for smaller sample sizes. 


\section{Acknowledgement}

We are very much thankful to Mr. AnimeshSrivastava, undergraduate studentIITKharagpur, INDIA for carrying out numerical calculations in R- language.

\section{References}

1. Aitchison,J. and Dunsmore,I.R.(1975): Statistical Prediction Analysis London,Cambridge University Press.

2. Altissimo, F., Corradi, V.(2003).Strong rules for detecting the number of breaks in a time series, J. Econometrics 117(2):2007-244.

3. Basu, A.P. andEbrahimi, N. (1991): "Bayesian approach to life testing and Reliability estimation using asymmetric loss function" Jour. of Stat. Planning \& Inf. 29 (1991) 21-31.

4. Berger,J.O.(1985): Statistical Decision Theory and Bayesian Analysis,Springer Verlag.

5. Braess, D., Dette, H.(2004). The asymptotic minimax risk for the estimation of constrained binomial and multinomial probabilities. Sankhyaind. J. statist.66(4);707-732.

6. Broemeling, L.D. (1985). Bayesian analysis of linear models. New York; Marcel-Dekker.

7. Broemeling, L.D., Tsurumi, H. (1987). Econometrics and Structural Shift. New York; Marcel-Dekker.

8. Boudjellaba, H., MacGibbon, B. and Sawyer, P., 2001, On Exact Inference for Change in a Poisson Sequence, Communications in Statistics A: Theory and Methods, 30(3), 407-434.

9. Calabria, R., Pulcini, G. (1994). An engineering approach to Bayes estimation for the weibull distribution. Micro Electron Reliab.34; 789-802.

10. Calabria, R., Pulcini, G.(1996). Point estimation under asymmetric loss functions for left truncated exponential samples. Commun. Stats. Theor. Meth.25(3);585-600.

11. Chib, S.(1998). Estimation and comparison of multiply shift point models J. Econometrics 86(2); 221-241.

12. Chin Choy, J.H. Broemeling, L.D.(1980). Some Bayesian inferences for a changing linear model. Technometrics 22;71-78.

13. Fiteni, I.(2004). T-estimators regression models with structural shift of unknown location. J.Econometrics 119(1);19-44.

14. Fotopoulos, S.B. and Jandhyala, V.K. (2001). Maximum likelihood estimation of a shift-point for exponentially distributed random variables. Statist. and Prob. 
15. Haccou, P., Meelis, E. and Geer, S. (1988). The likelihood ratio test for the shift point problem for exponentially distributed random variables. Stochastic Process and Their Applications, 27, 121-139.

16. Hinkley, D.V. (1970). Inference about the shift-point in a sequence of random variables. Biometrika, 57(1), 1-17.

17. Hinkley, D.V. and Hinkley, E.A. (1970). Inference about the chance-point in a sequence of binomial variables. Biometrika, 57(3), 477-488.

18. Jandhyala, V.K. and Fotopoulos, S.B. (1999). Capturing the distributional behaviour of the maximum likelihood estimator of a shift point. Biometrika, 86(1), 129-140.538 Estimation of shift points in a homogeneous Poisson process.

19. Lim, T.O.,Soraya, A., Ding, L.M., Morad, Z. (2002). Assuming doctor's competence; application of CUSUM techique in monitoring doctor's performance. Int.J.Qual. Health Care 14(3);251-258.

20. Montgomery,J.G.(2001), Introduction to statistical quality control. New York; John Wiley and Sons.

21. Normstrom, J.G.(1996). The use of precautionary loss function in risk analysis IEEE Trans. Reliab., 45(3),400-403.

22. Ohtani,K.(1995). Generalized Ridge regression estimators under the linex loss function Statist. Pap. 36;99-110.

23. Pandya, M., Jani, P.N.(2006). Bayesian estimation of shift point in inverse Weibull sequence. Commun, Statist. Theor. Meth. 35(10);2223-2237.

24. Parsian, A., Krimani,S.N.U.A.(2002). Estimation under linex loss function. Handbook of Applied Econometrics and Statistical inference, Statistics Textbook and Monograph.165. New York: marcel Dekker, pp.53-76.

25. Shah, J.B., Patel, M.N.(2007). Bayes estimation of shift point in geometric sequence. Commun. Statist. Theor. Meth.36(6);1139-1151.

26. Shah, J.B., Patel, M.N.(2009). Bayes Estimation of Shift Point in Normal Sequence and Its Application to Statistical Process Control. Commun. Statist. Theor. Meth. 38;560-572.

27. Varian,H.R.(1975). A Bayesian approach to real estate assessment. In: Feigner,Z.,ed. Studies in Bayesian Econometrics and Statistics and Statistics in Honor of Leonard J.Savage. Amsterdam: North Holland.

28. Worsley, K.J. (1986). Confidence region and test for a shift-point in a sequence of exponential family random variables. Biometrika, 73(1), 91-104.

29. Wu,Z., Shamsuzzaman, M.,Pan, E.S.(2004). Optimization design of the control chart based on Taguchi's loss function and random process shifts. Int.J. Product. Res.42:379-390. 
30. Wu,Z.Tian,Y.(2005). Weighted-loss-function CUSUM chart for monitoring mean and variance of a production process. Int. J. Product. Res. 43:30273044.

31. Zack, S. (1983). Survey of classical and Bayesian approaches to the shift point problem: fixed sample and sequential procedures for testing and estimation. Recent Advances in Statistics. Herman Chernoff Best Shrift. New York: Academic Press.

32. Zellner, A.(1986). Bayesian estimation and prediction using asymmetric loss function. J. Amer. Statist. 